Cochrane Database of Systematic Reviews

\title{
High-flow nasal cannula therapy for respiratory support in children
} (Review)

Mayfield S, Jauncey-Cooke J, Hough JL, Schibler A, Gibbons K, Bogossian F

Mayfield S, Jauncey-Cooke J, Hough JL, Schibler A, Gibbons K, Bogossian F. High-flow nasal cannula therapy for respiratory support in children.

Cochrane Database of Systematic Reviews 2014, Issue 3. Art. No.: CD009850. DOI: 10.1002/14651858.CD009850.pub2.

www.cochranelibrary.com 
TABLE OF CONTENTS

ABSTRACT 1

PLAIN LANGUAGE SUMMARY

BACKGROUND

OBJECTIVES

METHODS

RESULTS

Figure 1.

DISCUSSION

AUTHORS' CONCLUSIONS

ACKNOWLEDGEMENTS

REFERENCES

CHARACTERISTICS OF STUDIES

APPENDICES

WHAT'S NEW

CONTRIBUTIONS OF AUTHORS

DECLARATIONS OF INTEREST

DIFFERENCES BETWEEN PROTOCOL AND REVIEW

INDEX TERMS 
[Intervention Review]

\section{High-flow nasal cannula therapy for respiratory support in children}

Sara Mayfield1,2, Jacqueline Jauncey-Cooke2,3,4, Judith L Hough 5,6 , Andreas Schibler ${ }^{3}$, Kristen Gibbons ${ }^{7}$, Fiona Bogossian²

1Patient Safety and Quality Service, Children's Health Queensland Hospital and Health Service, South Brisbane, Australia. ${ }^{2}$ School of Nursing, Midwifery and Social Work, The University of Queensland, St Lucia, Australia. ${ }^{3}$ Paediatric Critical Care Research Group, Mater Research Institute - The University of Queensland, South Brisbane, Australia. ${ }^{4}$ Learning and Workforce Development, Children's Health Queensland Hospital and Health Service, South Brisbane, Australia. 5 Program for Optimising Outcomes for Mothers and Babies at Risk, Mater Research Institute, The University of Queensland, and The Physiotherapy Department, Mater Health Services, South Brisbane, Australia. ${ }^{6}$ School of Physiotherapy, Australian Catholic University, Banyo, Australia. ${ }^{7}$ Mater Research Institute - The University of Queensland (MRI-UQ), South Brisbane, Australia

Contact: Sara Mayfield, Patient Safety and Quality Service, Children's Health Queensland Hospital and Health Service, Raymond Terrace, South Brisbane, Queensland, 4010, Australia.Sara.Mayfield@health.qld.gov.au.

Editorial group: Cochrane Emergency and Critical Care Group.

Publication status and date: Edited (no change to conclusions), published in Issue 12, 2018.

Citation: Mayfield S, Jauncey-Cooke J, Hough JL, Schibler A, Gibbons K, Bogossian F. High-flow nasal cannula therapy for respiratory support in children. Cochrane Database of Systematic Reviews 2014, Issue 3. Art. No.: CD009850. DOI: 10.1002/14651858.CD009850.pub2.

Copyright @ 2018 The Cochrane Collaboration. Published by John Wiley \& Sons, Ltd.

\section{A B S T R A C T}

\section{Background}

Respiratory support is a central component of the management of critically ill children. It can be delivered invasively via an endotracheal tube or non-invasively via face mask, nasal mask, nasal cannula or oxygen hood/tent. Invasive ventilation can be damaging to the lungs, and the tendency to use non-invasive forms is growing. However, non-invasive delivery is often poorly tolerated by children. High-flow nasal cannula (HFNC) oxygen delivery is a relatively new therapy that shows the potential to reduce the need for intubation and be better tolerated by children than other non-invasive forms of support. HFNC therapy differs from other non-invasive forms of treatment in that it delivers heated, humidified and blended air/oxygen via nasal cannula at rates $\geq 2 \mathrm{~L} / \mathrm{kg} / \mathrm{min}$. This allows the user to deliver high concentrations of oxygen and to potentially deliver continuous distending pressure; this treatment often is better tolerated by the child.

\section{Objectives}

To determine whether HFNC therapy is more effective than other forms of non-invasive therapy in paediatric patients who require respiratory support.

\section{Search methods}

We searched the Cochrane Central Register of Controlled Trials (CENTRAL) (2013, Issue 4); MEDLINE via PubMed (January 1966 to April 2013); EMBASE (January 1980 to April 2013); CINAHL (1982 to April 2013); and LILACS (1982 to April 2013). Abstracts from conference proceedings, theses and dissertations and bibliographical references to relevant studies were also searched. We applied no restriction on language.

\section{Selection criteria}

We planned to included randomized controlled trials (RCTs) and quas-randomized trials comparing HFNC therapy with other forms of non-invasive respiratory support for children. Non-invasive support encompassed cot, hood or tent oxygen; low-flow nasal cannulae (flow rates $\leq 2 \mathrm{~L} / \mathrm{min}$ ); and continuous positive airway pressure (CPAP) or bilevel positive airway pressure (BiPAP) delivered via facial or nasal mask/cannula. Treatment failure was defined by the need for additional respiratory support. We excluded children with a diagnosis of bronchiolitis. 


\section{Data collection and analysis}

Two review authors independently assessed all studies for selection and data extraction. We used standard methodological procedures expected by The Cochrane Collaboration.

\section{Main results}

Our search yielded 922 records. A total of 109 relevant records were retrieved with reference to our search criteria. After duplicates and irrelevant studies were removed, 69 studies were further scrutinized. Of these, 11 studies involved children. No study matched our inclusion criteria.

\section{Authors' conclusions}

Based on the results of this review, no evidence is available to allow determination of the safety or effectiveness of HFNC as a form of respiratory support in children.

\section{PLAIN LANGUAGE SUMMARY}

\section{High-flow nasal cannula therapy for support of breathing in children}

We reviewed evidence on the effectiveness of high-flow nasal cannula (HFNC) therapy in supporting children's breathing. We found 11 studies in children.

\section{Background}

HFNC therapy delivers a mixture of air and oxygen via tubing that sits just inside the nostrils. For children hospitalized with breathing difficulties caused by conditions such as pneumonia or trauma or after surgery, HFNC therapy may help to support their breathing. This may reduce the need for other forms of breathing support such as life support. HFNC therapy can be used within the hospital ward setting, the emergency department or the intensive care unit. This Cochrane review is important because it assesses available evidence on the safety and effectiveness of HFNC compared with other forms of respiratory support, to help inform clinicians caring for children with breathing difficulties.

\section{Search date}

We searched medical databases from the 1950s until April 2013.

\section{Study characteristics}

We included studies on children from four weeks to 16 years of age. We searched for randomized controlled trials; however we excluded studies involving infants with bronchiolitis (a respiratory illness affecting infants that typically mimics a common cold) because children with this condition are included in another Cochrane review.

\section{Results}

We found 11 studies involving children; however none matched our criteria.

\section{Conclusion}

It is important that good-quality studies are completed to identify indications as to the use and effectiveness of HFNC therapy in supporting the breathing of ill children. 


\section{B A C K G R O U N D}

\section{Description of the condition}

Respiratory support is central to the care of critically ill children. Support may be needed because of underlying disease processes such as respiratory infection or pneumonia, neuromuscular disorders, cardiac conditions or cardiac failure, and as the result of other mechanisms such as upper airway obstruction, trauma and injury or postsurgical interventions. Respiratory support can be delivered non-invasively in the form of oxygen therapy, continuous positive airway pressure (CPAP) or bilevel positive airway pressure (BiPAP), or invasively via mechanical ventilation. Children with significant respiratory distress and hypoxaemia often require the latter. This may result in various forms of trauma to the lungs and airways, collectively known as ventilator-induced lung injury (VILI) (Dahlem 2003; The ARDS Network 2000).

Although VILI is the major concern with intubation and mechanical ventilation, other effects on the body need to be considered. Increased use of sedative drugs may lead to neuropathy or myopathy, which can increase recovery time. In turn, cardiovascular support in the form of drug infusions may be needed to maintain blood pressure. These requirements increase the costs of care provided to the child. Non-invasive methods of ventilation are an ideal method of providing respiratory support without the need for intubation and may avoid some of the additional harms associated with positive-pressure ventilation, such as ventilatorassociated pneumonia (VAP) (Glossop 2012).

Non-invasive ventilation can be as simple as oxygen therapy delivered via face mask, nasal cannula or head box or devices delivering CPAP/BiPAP via face mask or nasopharyngeal tubes, with pressure generated by a dedicated driver or water column (i.e. bubble CPAP) (Frey 2001; Frey 2003; Klein 1986). Devices delivering CPAP/BiPAP can reduce the work of breathing and improve functional residual capacity, potentially avoiding intubation, reducing VILI and VAP and preventing other possible causes of harm (Reid 1984; Thorsteinsson 2002).

Disadvantages of this method of delivery are that it is cumbersome, and the masks and tubes are poorly tolerated by young children and infants (McGinley 2009; Spentzas 2009; Yong 2005). Obtaining an adequate seal around the face of small children can be difficult, thereby making delivery of CPAP/BiPAP variable and resulting in ineffective ventilation. This is often due to the limited choice of face masks developed for children with a wide range of ages and stages of facial development. The need for a system that can deliver CPAP while being comfortable and well tolerated by children is an important consideration in providing non-invasive respiratory support.

\section{Description of the intervention}

High-flow nasal cannula (HFNC) therapy has recently been introduced for a range of patients from preterm infants to adults, addressing the need for a simple, effective method of providing respiratory support (Campbell 2006; McGinley 2009; McKiernan 2010; Shoemaker 2007). It offers an advantage over simple oxygen therapy in that the gas mixture can be heated and humidified, thereby reducing damage to upper airway mucosa, and the concentration of inspired oxygen can be titrated as required. This can prevent inflammatory reactions and the naso-pulmonary bronchoconstrictor reflex triggered by cold, dry air (Spentzas 2009). The mixed gas is delivered via a nasal cannula that sits just inside the nares. The flow rate delivered varies depending on the type of cannula used but can range from 4 to $70 \mathrm{~L} / \mathrm{min}$.

\section{How the intervention might work}

It has been shown that delivery of nasal air at high flow rates may cause incidental delivery of CPAP (Dysart 2009; Spence 2007; Wilkinson 2008). The effects of this are yet to be fully understood. It may be that the high flow flushes the dead space of the nasopharyngeal cavity, resulting in alveolar ventilation as a greater fraction of minute ventilation. It may also assist in the washout of carbon dioxide, which may then reduce apnoea secondary to hypercapnia and improve ventilation (Dysart 2009). High flow rates may also provide some amount of positive pressure and thereby overcome upper airway obstruction, again improving ventilation (McGinley 2009).

The amount of CPAP generated depends on the flow delivered relative to the size of the patient, the size of the nasal cannula used and the potential for leak around the nasal cannula (Kubicka 2008; Lampland 2009; Sreenan 2001). Three retrospective studies in paediatric populations assessing HFNC therapy have demonstrated that overall, ventilator days were significantly decreased after introduction of this therapy when compared with retrospective historical control groups (McKiernan 2010; Schibler 2011; Shoemaker 2007).

HFNC therapy has also been reported to be better tolerated by the patient than other forms of non-invasive ventilation (Roca 2010). This can reduce the need for the sedation required to help patients tolerate more invasive or uncomfortable forms of respiratory support.

\section{Why it is important to do this review}

HFNC therapy is an emerging treatment option for the respiratory support of children, especially in the intensive care unit. To date, most findings have been derived from neonatal and adult studies, with little clinical experience reported in the paediatric population (McKiernan 2010). Clinical experience in the paediatric population is reported in case reports and observational studies; few randomized controlled trials are reported (Mayfield 2013; McGinley 2009; Spentzas 2009). The Cochrane review of HFNC therapy from the Cochrane Neonatal Group found only four eligible, randomized controlled trials and concluded that evidence was insufficient to determine effectiveness, and more research was needed (Wilkinson 2011). Two further reviews of HFNC therapy are under way: in the adult population (Corley 2012) and in infants with bronchiolitis (Beggs 2012). This review differs in that it includes studies of children with a broader age range and more diverse pathophysiologies such as type 1 and 2 respiratory failure, parenchymal lung disease, neuromuscular disorders, respiratory drive disorders and airway obstruction.

HFNC therapy has the potential to improve outcomes such as reduced intubation and invasive ventilation (McKiernan 2010; Schibler 2011; Wing 2012) in critically ill children. It is readily applied and is not resource or cost intensive. Staff can easily be trained in the application of HFNC therapy and in the care of children using this therapy. It may also reduce the length of intubation, as HFNC holds potential to transition between 
extubation and low-flow nasal cannula oxygen delivery. An additional advantage is that children requiring this therapy may be cared for outside of the paediatric intensive care unit (PICU). However potential risks are associated with its use, such as air leak syndrome, which has been described in a case report (Hedge 2013), and other risks extrapolated from the neonatal population, such as nasal trauma and abdominal overdistention (Kopelman 2003). These potential risks and benefits need to be assessed in the paediatric population.

\section{OB JECTIVES}

To determine whether HFNC therapy is more effective than other forms of non-invasive therapy in paediatric patients who require respiratory support.

\section{METHODS}

\section{Criteria for considering studies for this review}

\section{Types of studies}

We included prospective randomized controlled trials (RCTs) and quasi-randomized studies.

\section{Types of participants}

We included paediatric participants from four weeks corrected age to 16 years of age requiring respiratory support for type 1 and 2 respiratory failure, parenchymal lung disease, neuromuscular disorders, respiratory drive and airway obstruction. We excluded a study in children with bronchiolitis.

\section{Types of interventions}

What constitutes 'high flow' has not been well described in the literature, nor has it been universally determined. Most paediatric studies have been limited to using devices that deliver flow rates in infants from 4 to $8 \mathrm{~L} / \mathrm{min}$ (Arora 2012; Schibler 2011). Older children may have up to $30 \mathrm{~L} / \mathrm{min}$ delivered (McGinley 2009). For the purposes of this review, high-flow nasal oxygen was defined as the delivery of heated, humidified oxygen or blended oxygen with air via nasal cannula at flow rates greater than $2 \mathrm{~L} / \mathrm{min}$. HFNC therapy was compared with other means of non-invasive respiratory support, such as cot, hood or tent oxygen; low-flow nasal cannula (flow rates $\leq 2 \mathrm{~L} / \mathrm{min}$ ); and continuous positive airway pressure (CPAP) or bilevel positive airway pressure (BiPAP).

\section{Types of outcome measures}

\section{Primary outcomes}

1. Hospital mortality.

2. Intubation rate.

3. Treatment failure (defined as the need for additional respiratory support)

\section{Secondary outcomes}

1. Duration of any form of respiratory support in hours (mechanical ventilation, non-invasive ventilation, high-flow nasal cannula).

2. Length of stay in hospital in days.

3. Clinical severity score.

4. Length of paediatric intensive care unit (PICU) stay in days.

5. Complications.
- Air leaks (pneumothorax, pneumomediastinum, pneumopericardium or pulmonary interstitial emphysema (PIE)) reported individually or as a composite outcome.

- Nasal trauma (defined as erythema or erosion of the nasal mucosa, nares or septum as assessed by a blinded observer).

- Barotrauma.

- Gastrointestinal distention.

\section{Search methods for identification of studies}

\section{Electronic searches}

We obtained all relevant studies irrespective of language or publication status (published, unpublished, in press and in progress) using the following methods. We applied no limits in terms of language or year of publication.

We searched Issue 4, 2013 of the Cochrane Central Register of Controlled Trials (CENTRAL, see Appendix 1); MEDLINE via Ovid SP (January 1966 to April 2013, see Appendix 2); EMBASE via Ovid SP (January 1980 to April 2013, see Appendix 3); CINAHL via EBSCO Host (1982 to April 2013, see Appendix 4); and LILACS via the BIREME interface (1982 to April 2013, see Appendix 5).

We also searched the electronic databases of higher-degree theses for relevant unpublished trials: Index to Theses (1950 to date), Australian Digital Theses Program (1997 to April 2013) and Proquest Digital Dissertations (1980 to April 2013).

We then combined our MEDLINE search strategy with the Cochrane highly sensitive search strategy for identifying RCTs, as suggested in the Cochrane Handbook for Systematic Reviews of Interventions (Higgins 2011). We adopted the MEDLINE search strategy for searching in all other databases.

For ongoing trials, we searched the MetaRegister of Controlled Trials (http://www.controlledtrials.com/) and the National Research Register (http://clinicaltrials.gov/).

\section{Searching other resources}

We handsearched citations from included studies.

\section{Data collection and analysis}

We used standard methodological procedures expected by The Cochrane Collaboration.

\section{Selection of studies}

We used the search strategy described to obtain titles and abstracts of studies that may be relevant to the review. Two review authors (SM and JJ-C) independently performed this screening. Studies that were not applicable were discarded. We found no ongoing studies that matched our search criteria.

\section{Data extraction and management}

We adapted the standardized Cochrane Anasthesia Review Group (CARG) data extraction form (Appendix 6) to capture relevant data specific to this review. We (SM and $\mathrm{JJ}-\mathrm{C}$ ) used this form independently to extract and collect data from the relevant study. No disagreements arose. 


\section{Assessment of risk of bias in included studies}

No studies were eligible for assessment of risk of bias. However, we planned to assess risk of bias using the following domains with judgements of high, low or uncertain.

1. Selection bias: incorporating random sequence generation and allocation concealment.

2. Performance bias: blinding of participants and personnel.

3. Detection bias: blinding of outcome assessment.

4. Attrition bias: incomplete outcome data.

5. Reporting bias: selective reporting.

6. Other bias: other sources of bias.

\section{Measures of treatment effect}

No studies were found that could be included in this review. Excluded studies were tabulated with the reasons for exclusion documented in the Characteristics of excluded studies.

We planned to manage dichotomous outcome data, such as mortality, by using risk ratios (RRs) to determine effect and by displaying them in a table. For continuous data, we planned to collect means and standard deviations and to display them in a table. If different scales were used to measure continuous data, we would have calculated the standardized mean difference. Outcomes from comparable trials would have used $95 \%$ confidence intervals to estimate treatment effect. We would use forest plots to graphically compare treatment effect with risk ratio for dichotomous data and with mean difference for continuous outcomes.

\section{Unit of analysis issues}

The unit of analysis was the individual child. We expected to find parallel-group study designs and no cross-over studies. As none of the studies included in this review were randomized at cluster level, unit of analysis was not an issue.

\section{Dealing with missing data}

If eligible studies with missing data were found, we planned to contact the corresponding author.

\section{Assessment of heterogeneity}

We planned to analyse heterogeneity using the $\mathrm{Chi}^{2}$ test on $\mathrm{N}-1$ degrees of freedom, with an alpha of 0.1 used for statistical significance, along with the $\mathrm{I}^{2}$ statistic (Higgins 2011).

\section{Assessment of reporting biases}

We planned to assess publication bias or small-study effects by preparing a funnel plot. We planned to test for funnel plot asymmetry if more than 10 studies were included in the metaanalysis. We planned to obtain published and unpublished studies as a way of addressing reporting bias.

\section{Data synthesis}

We planned to review the summary tables of included trials to identify clinical heterogeneity amongst trials. If two or more randomized trials had been found with comparable populations undergoing similar interventions, we would have conducted a meta-analysis with a random-effects model using RevMan 5.2.

\section{Subgroup analysis and investigation of heterogeneity}

No studies were found to permit subgroup analyses or exploration of heterogeneity (Sutton 2008).

\section{Sensitivity analysis}

No studies were found to allow sensitivity analysis.

\section{Summary of findings}

We planned to use the principles of the GRADE system (Guyatt 2008) to assess the quality of the body of evidence associated with the following specific outcomes in our review.

1. Mortality.

2. Intubation.

3. Failure of treatment or escalation to non-invasive ventilation.

4. Length of PICU stay.

5. Length of time on any form of respiratory support.

6. Oxygenation and respiratory assessment tools.

However, no studies were identified for inclusion.

\section{RES U L T S}

\section{Description of studies}

See Characteristics of excluded studies.

\section{Results of the search}

Our search yielded 922 records. After duplicates and irrelevant references were removed, 69 were further scrutinized. Eleven studies involved children. No study met our criteria (Figure 1). 
Figure 1. Study flow diagram.

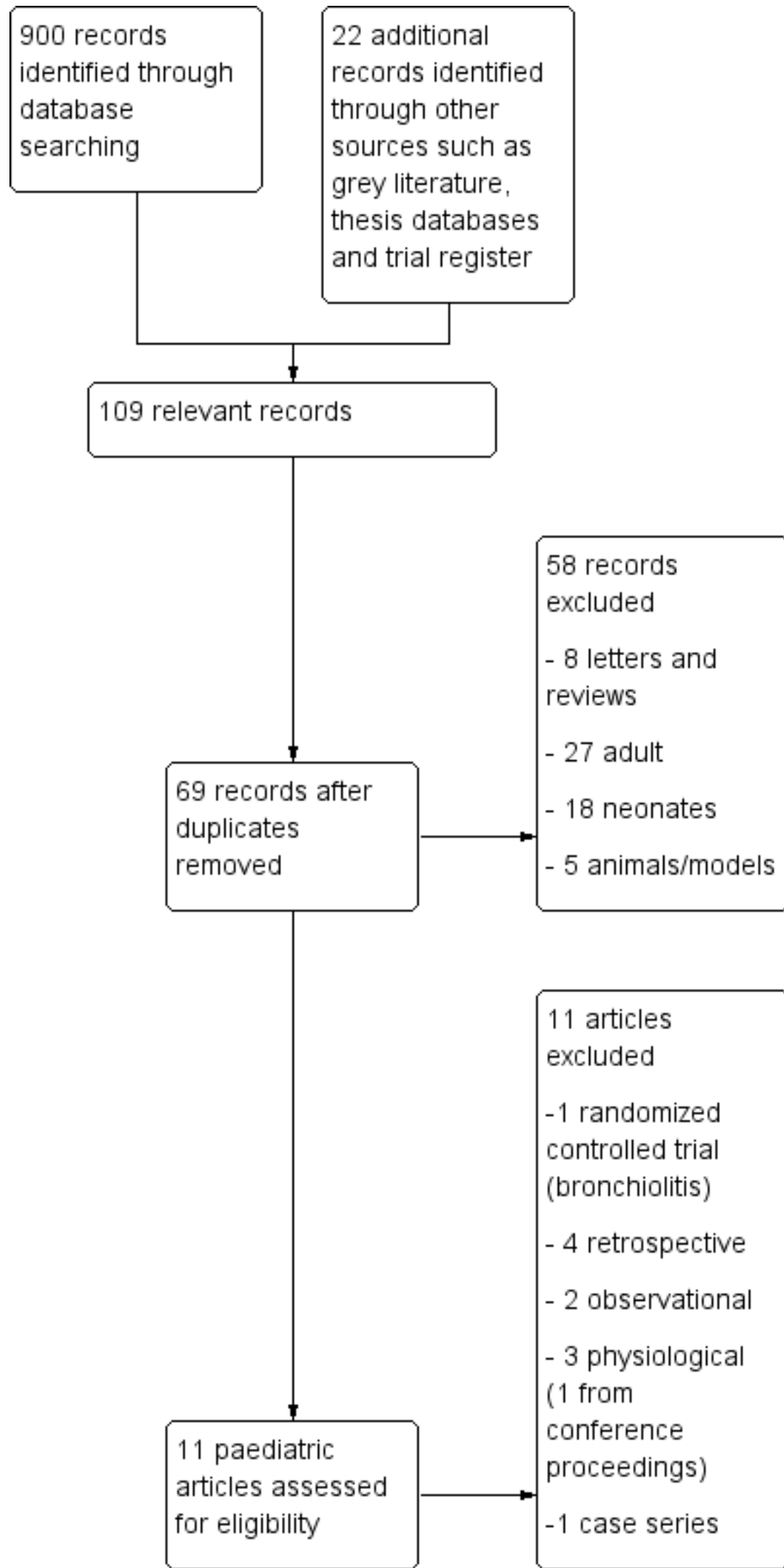




\section{Included studies}

No studies met our inclusion criteria.

\section{Excluded studies}

Ten studies did not meet the criteria of being randomized or quasi-randomized (Abboud 2012; Arora 2012; Hedge 2013; Hough 2011; McGinley 2009; McKiernan 2010; Milesi 2013; Schibler 2011; Spentzas 2009; Wing 2012). One randomized controlled trial was excluded because it included infants with bronchiolitis (Hilliard 2012). Details are listed in the Characteristics of excluded studies.

\section{Risk of bias in included studies}

N/A.

\section{Allocation}

N/A.

\section{Blinding}

N/A.

\section{Incomplete outcome data}

N/A.

\section{Selective reporting}

N/A.

\section{Other potential sources of bias}

N/A.

\section{Effects of interventions}

N/A.

\section{DISCUSSION}

\section{Summary of main results}

We found no randomized controlled trials of HFNC therapy in children older than four weeks of age requiring respiratory support for type 1 or 2 respiratory failure, parenchymal lung disease, neuromuscular disorders, respiratory drive or airway obstruction.

\section{Overall completeness and applicability of evidence}

N/A.

\section{Quality of the evidence}

N/A.

\section{Potential biases in the review process}

We believe that any bias in this review is of low probability. We ensured that language would not be a bias by imposing no restrictions on such. We used a well-constructed search strategy to minimize the chance of missing randomized controlled trials that fulfilled our inclusion criteria.

\section{Agreements and disagreements with other studies or reviews}

This review supports the conclusion of other studies and reviews conducted to evaluate HFNC therapy (Lee 2013; Wilkinson 2011) in that evidence of robust quality is insufficient to permit determination of the superiority of HFNC therapy over other established forms of non-invasive ventilation for children with moderate to severe respiratory compromise. Further studies are needed to quantify this and to identify clinical indicators regarding its use.

\section{AUTHORS'CONCLUSIONS}

\section{Implications for practice}

Based on the results of this review, no evidence can be found to allow determination of the safety or effectiveness of HFNC therapy as a form of respiratory support in children.

\section{Implications for research}

It is acknowledged that while the number of retrospective, observational and physiological studies surrounding the support of HFNC therapy for respiratory support in children is increasing, adequately powered randomized controlled trials are needed. HFNC therapy must be compared with CPAP and other forms of noninvasive respiratory support. Clinically important outcomes, such as escalation to CPAP or intubation, length of stay and duration of treatment, need to be assessed. With such a broad range of ages and disease processes in children, an aim of further research should be to establish which subgroups benefit from HFNC therapy.

\section{ACKNOWLEDGEMENTS}

We would like to thank Bronagh Blackwood (content editor) and David Turner, Christophe Milési, Mark W Davies and Oliver Karam (peer reviewers) for their help and editorial advice during the preparation of this systematic review.

We would also like to thank Mathew Zacharis (content editor), Cathal Walsh (statistical editor) and Dominic Wilkinson, Oliver Karam and Mark Davies (peer reviewers) for their help and editorial advice during the preparation of the protocol for the systematic review. 


\section{RE F E R E N C E S}

\section{References to studies excluded from this review}

\section{Abboud 2012 \{published data only\}}

Abboud P, Roth P, Skiles C, Stolfi A, Rowin M. Predictors of failure in infants with viral bronchiolitis treated with high-flow, high-humidity nasal cannula therapy. Pediatric Critical Care 2012;13(6):e343-9. [PUBMED: 22805160]

\section{Arora 2012 \{published data only\}}

* Arora B, Mahajan P, Zidan M, Sethuraman U. Nasopharyngeal airway pressures in bronchiolitis patients treated with highflow nasal cannula oxygen therapy. Pediatric Emergency Care 2012;28:1179-84. [PUBMED: 23114244]

\section{Hedge 2013 \{published data only\}}

Hedge S, Prodhan P. Serious air leak syndrome complicating high-flow nasal cannula therapy: a report of 3 cases. Pediatrics 2013;131(3):e1-6. [PUBMED: 23382446]

\section{Hilliard 2012 \{published data only\}}

Hilliard T, Archer N, Hole L, Heraghty J, Cottis H, Mills K, et al. Pilot study of vapotherm oxygen delivery in moderately severe bronchiolitis. Archives of Disease in Childhood 2012;97:182-3. [DOI: 10.1136/archdischild-2011-301151; PUBMED: 22100741]

\section{Hough 2011 \{published data only\}}

Hough JL, Pham TMT, Schibler A. Delivery of high flow nasal prong oxygen: the effect CPAP exposed. Pediatric Critical Care Medicine Conference: 6th World Congress on Pediatric Critical Care. 2011; Vol. 12 (3 Suppl 1):A7.

\section{McGinley 2009 \{published data only\}}

* McGinley B, Halbower A, Schwartz AR, Smith PL, Patil SP, Schneider $\mathrm{H}$. Effect of a high-flow open nasal cannula system on obstructive sleep apnoea in children. Pediatrics 2009;124:179-88. [PUBMED: 19564298]

\section{McKiernan 2010 \{published data only\}}

* McKiernan C, Chua LC, Vistanier PF, Allen H. High flow nasal cannulae therapy in infants with bronchiolitis. Journal of Pediatrics 2010;156:634-8. [PUBMED: 20036376 ]

\section{Milesi 2013 \{published data only\}}

Milesi C, Baleine J, Matecki S, Durand S, Combes C, Novais A, et al. Is treatment with a high flow nasal cannula effective in acute viral bronchiolitis? A physiologic study. Intensive Care Medicine 2013;39:1088-94. [DOI: 10.1007/s00134-013-2879-y; PUBMED: 23494016]

\section{Schibler 2011 \{published data only\}}

* Schibler A, Pham TMT, Dunster KR, Foster K, Barlow A, Gibbons K, et al. Reduced intubation rates for infants after introduction of high flow nasal prong oxygen delivery. Intensive Care Medicine 2011;3:847-52. [PUBMED: 21369809]

\section{Spentzas 2009 \{published data only\}}

Spentzas T, Minarik M, Patters AB, Vinson B, Stidham G. Children with respiratory distress treated with high-flow nasal cannula.
Journal of Intensive Care Medicine 2009;24(5):323-8. [PUBMED: 19703816]

\section{Wing 2012 \{published data only\}}

Wing R, James C, Maranda L, Armsby C. Use of high-flow nasal cannula support in the emergency department reduces the need for intubation in pediatric acute respiratory insufficiency. Pediatric Emergency Care 2012;28:1117-23. [PUBMED: 23114231]

\section{Additional references}

\section{Beggs 2012}

Beggs, Wong ZH, Kaul S, Ogden KJ, Walters JAE. Highflow nasal cannula therapy for infants with bronchiolitis. Cochrane Database of Systematic Reviews 2012, Issue 2. [DOI: 10.1002/14651858.CD009609]

\section{Campbell 2006}

Campbell DM, Shah PS, Shah V, Kelly EN. Nasal continuous positive airway pressure from high flow cannula versus Infant Flow for preterm infants. Journal of Perinatology 2006;26:546-9. [PUBMED: 16837929]

\section{Corley 2012}

Corley A, Rickard CM, Aitken LM, Johnston A, Barnett A, Fraser JF. High flow nasal cannulae for respiratory support in adult intensive care patients. Cochrane Database of Systematic Reviews 2012, Issue 11. [DOI: 10.1002/14651858.CD010172; CD10172]

\section{Dahlem 2003}

Dahlem P, Van Aalderen WM, Hamaker ME, Dijkfraaf MG, Bos AP. Incidence and short-term outcome of acute lung injury in mechanically ventilated children. European Respiratory Journal 2003;22(6):980-5. [PUBMED: 14680089]

\section{Dysart 2009}

Dysart K, Miller TL, Wolfson MR, Shaffer TH. Reserach in high flow therapy: mechanisms of action. Respiratory Medicine 2009;103:1400-5. [PUBMED: 19467849]

\section{Frey 2001}

Frey B, McQuillan PJ, Shann F, Freezer N. Nasopharyngeal oxygen therapy produces positive end-expiratory pressure in infants. European Journal of Pediatrics 2001;160:556-60. [PUBMED: 11585079 ]

\section{Frey 2003}

Frey B, Shann F. Oxygen administration in infants. Archives of Disease in Childhood: Fetal and Neonatal Edition 2003;88(2):84-8. [PUBMED: 12598492]

\section{Glossop 2012}

Glossop AJ, Shepherd N, Bryden DC, Mills GH. Non-invasive ventilation for weaning, avoiding reintubation after extubation and in the postoperative period: a meta-analysis. British Journal 
of Anaesthesia 2012;109(3):305-314. [DOI: 10.1093/bja/aes305; PUBMED: 22879654]

\section{Guyatt 2008}

Guyatt GH, Oxman AD, Kunz R, Vist GE, Falck-Ytter Y, Schunemann HJ. What is "quality of evidence" and why is it important to clinicians?. BMJ 2008;336:995-8. [PUBMED: 18456631]

\section{Higgins 2011}

Higgins JPT, Green S, editors. Cochrane Handbook for Systematic Reviews of Interventions, Version 5.1.0 [updated March 2011] . The Cochrane Collaboration, 2011. www.cochrane-handbook.org.

\section{Klein 1986}

Klein M, Reynolds LG. Relief of sleep-related oropharyngeal airway obstruction by continuous insufflation of the pharynx. Lancet 1986;1:935-9. [PUBMED: 2871240]

\section{Kopelman 2003}

Kopelman AE, Holbert D. Use of oxygen cannulas in extremely low birthweight infants is associated with mucosal trauma and bleeding, and possibly with coagulase-negative staphylococcal sepsis. Journal of Perinatology 2003;23:94-7. [PUBMED: 12673256]

\section{Kubicka 2008}

Kubicka ZJ, Limauro J, Darnell RA. Heated humidified high-flow nasal cannula therapy: yet another way to deliver continuous positive airway pressure?. Pediatrics 2008;121:82-8. [PUBMED: 18166560]

\section{Lampland 2009}

Lampland AL, Plumm B, Meyers PA, Worwa CT, Mammel MC. Observational study of humidified high flow nasal cannula compared with nasal continuous positive airway pressure. Journal of Pediatrics 2009;154:177-82. [PUBMED: 18760803]

\section{Lee 2013}

Lee JH, Rehder KJ, Williford L, Cheifetz IM, Turner DA. Use of high flow nasal cannula in critically ill infants, children and adults: a critical review of the literature. Intensive Care Medicine 2013;39:247-57. [DOI: 10.1007/s00134-012-2743-5; PUBMED: 23143331]

\section{Mayfield 2013}

Mayfield S, Jauncey-Cook J, Bogossian F. A case series of paediatric high flow nasal cannula therapy. Australian Critical Care 2013;26:189-92. [DOI: 10.1016/j.aucc.2013.05.004; PUBMED: 23891472]

\section{Reid 1984}

Reid LM. Lung growth in health and disease. British Journal of Diseases of the Chest 1984;78:113-4. [PUBMED: 6372845]

\section{RevMan 5.2 [Computer program]}

The Nordic Cochrane Centre, The Cochrane Collaboration. Review Manager (RevMan). Version 5.2. Copenhagen: The Nordic Cochrane Centre, The Cochrane Collaboration, 2011.

\section{Roca 2010}

Roca O, Riera J, Torres F, Masclans J. High-flow oxygen therapy in acute respiratory failure. Respiratory Care 2010;55(4):408-13. [PUBMED: 20406507]

\section{Shoemaker 2007}

Shoemaker MT, Pierce MR, Yoder BA, DiGeronimo RJ. High flow nasal cannula versus nasal CPAP for neonatal respiratory disease: a retrospective study. Journal of Perinatology 2007;27:85-91. [PUBMED: 17262040]

\section{Spence 2007}

Spence KL, Murphy D, Kilian C, McGonigle R, Kilani RA. High flow nasal cannula as a device to provide continuous positive airway pressure in infants. Journal of Perinatology 2007;27:772-5. [PUBMED: 17762844 ]

\section{Sreenan 2001}

Sreenan C, Lemke RP, Hudson-Mason A, Osiovich H. High-flow nasal cannulae in the management of apnoea of prematurity: a comparison with conventional nasal continuous positive airway pressure. Pediatrics 2001;107:1081-3. [PUBMED: 11331690]

\section{Sutton 2008}

Sutton AH, HIggins JP. Recent developments in meta-analysis. Statistics in Medicine 2008;27:625-50. [PUBMED: 17590884]

\section{The ARDS Network 2000}

The ARDS Network. Ventilation with lower tidal volumes as compared with traditional tidal volumes for acute lung injury and the acute respiratory distress syndrome. New England Journal of Medicine 2000;342:1301-8. [PUBMED: 10793162]

\section{Thorsteinsson 2002}

Thorsteinsson A, Werner O, Jonmaker C, Larsson A. Airway closure in anaesthetized infants and children: the influence of inspiratory pressures and volumes. Acta Anaesthesiologica Scandinavica 2002;46:529-36. [PUBMED: 12027847]

\section{Wilkinson 2008}

Wilkinson DJ, Anderson CC, Smith K, Holberton J. Pharyngeal pressure with high-flow nasal cannulae in premature infants. Journal of Perinatology 2008;28:42-7. [PUBMED: 17989697]

\section{Wilkinson 2011}

Wilkinson D, Andersen C, O'Donnell CPF, De Paoli AG. High flow nasal cannula for respiratory support in preterm infants. Cochrane Database of Systematic Reviews 2011, Issue 5. [DOI: 10.1002/14651858.CD006405.pub2; PUBMED: 21563154 ]

\section{Yong 2005}

Yong SC, Chen SJ, Boo NY. Incidence of nasal trauma associated with nasal prong versus nasal mask during continuous positive airway pressure treatment in very low birthweight infants: a randomised control study. Archives of Diseases in Childhood. Fetal and Neonatal Edition 2005;90:F480-3. [PUBMED: 15941825] 
References to other published versions of this review

Mayfield 2012

Mayfield S, Jauncey-Cooke J, Hough JL, Schibler A, Gibbons K, Bogossian F. High flow nasal cannula therapy for respiratory support in children. Cochrane Database of Systematic Reviews 2012, Issue 5. [DOI: 10.1002/14651858.CD009850]

* Indicates the major publication for the study

\section{CHARACTERISTICS OF STUDIES}

Characteristics of excluded studies [ordered by study ID]

\begin{tabular}{|c|c|}
\hline Study & Reason for exclusion \\
\hline Abboud 2012 & $\begin{array}{l}\text { Retrospective chart review of all patients admitted to intensive care with a diagnosis of viral bron- } \\
\text { chiolitis from } 2006 \text { to } 2010.113 \text { patients met inclusion criteria of }<12 \text { months, initiation of HFNC on } \\
\text { admission }\end{array}$ \\
\hline Arora 2012 & $\begin{array}{l}\text { Prospective observational study to measure nasopharyngeal effects of HFNC in infants with bron- } \\
\text { chiolitis. } 25 \text { infants enrolled }\end{array}$ \\
\hline Hedge 2013 & Case series of three patients with air leak syndrome who were also treated with HFNC \\
\hline Hilliard 2012 & $\begin{array}{l}\text { Prospective randomized controlled trial comparing HFNC versus head box oxygen therapy. } 19 \text { par- } \\
\text { ticipants enrolled, all with viral bronchiolitis }\end{array}$ \\
\hline Hough 2011 & $\begin{array}{l}\text { Prospective physiological study comparing HFNC at different flow rates. } 13 \text { participants enrolled, } \\
\text { all with bronchiolitis }\end{array}$ \\
\hline McGinley 2009 & $\begin{array}{l}\text { Prospective observational study of } 12 \text { participants with obstructive apnoea-hypopnoea syndrome } \\
\text { treated with nasal insufflation at } 20 \mathrm{~L} / \mathrm{min}\end{array}$ \\
\hline McKiernan 2010 & $\begin{array}{l}\text { Retrospective chart review comparing intubation rates of infants with bronchiolitis admitted be- } \\
\text { fore and in the season after HFNC was implemented. } 115 \text { participants included in the review }\end{array}$ \\
\hline Milesi 2013 & $\begin{array}{l}\text { Prospective physiological study of } 21 \text { infants }<\text { six months with viral bronchiolitis and HFNC thera- } \\
\text { py. Pharygneal and oesophageal pressures measured at different flow rates }\end{array}$ \\
\hline Schibler 2011 & $\begin{array}{l}\text { Retrospective chart review of infants }<24 \text { months admitted to PICU between January } 2005 \text { and De- } \\
\text { cember 2009, requiring HFNC therapy. } 298 \text { infants included in the review }\end{array}$ \\
\hline Spentzas 2009 & $\begin{array}{l}\text { Observational study of all participants (newborn to } 12 \text { years) requiring HFNC, admitted between } \\
\text { January } 2005 \text { and January } 2007 \text { to PICU. } 46 \text { participants included in the study }\end{array}$ \\
\hline Wing 2012 & $\begin{array}{l}\text { Retrospective chart review of all patients admitted from ED to PICU with acute respiratory insuffi- } \\
\text { ciency from January } 2006 \text { to December } 2009 \text {. Patients admitted before HFNC availability were com- } \\
\text { pared with patients admitted after HFNC became available (two cohorts, before and after imple- } \\
\text { mentation of clinical guidelines). } 848 \text { participants included in the review }\end{array}$ \\
\hline
\end{tabular}

\section{APPENDICES}

\section{Appendix 1. CENTRAL search strategy}

\#1 MeSH descriptor Oxygen Inhalation Therapy explode all trees

\#2 intubation rates*

\#3 (\#1 AND \#2)

\#4 ((high flow (nasal or prong or cannula)) or (nasal near oxygen)):ti,ab

\#5 (\#3 OR \#4) 
Search from Issue 42013.

\section{Appendix 2. MEDLINE (Ovid SP) search strategy}

1. (exp Oxygen Inhalation Therapy/ and intubation rates*.af.) or (high flow adj3 (nasal or prong or cannula)).mp. or (nasal adj3 oxygen).mp.

2. ((randomized controlled trial or controlled clinical trial).pt. or randomized.ab. or placebo.ab. or drug therapy.fs. or randomly.ab. or trial.ab. or groups.ab.) not (animals not (humans and animals)).sh.

3. 1 and 2

Search from January 1966- April 2013.

\section{Appendix 3. EMBASE (Ovid SP) search strategy}

1. (exp oxygen therapy/ and intubation rates*.af.) or (high flow adj3 (nasal or prong or cannula)).mp. or (nasal adj3 oxygen).mp.

2. (randomized-controlled-trial/ or randomization/or controlled-study/or multicenter-study/or phase-3-clinical-trial/or phase-4-clinicaltrial/ or double-blind-procedure/ or single-blind-procedure/ or (random* or cross?over* or multicenter* or factorial* or placebo* or volunteer $\left.{ }^{\star}\right) \cdot m p$. or ((singl* or doubl* or trebl* or tripl $\left.{ }^{\star}\right)$ adj3 (blind ${ }^{\star}$ or mask $\left.{ }^{\star}\right)$ ).ti,ab. or (latin adj square).mp.) not (animals not (humans and animals)).sh.

3. 1 and 2

Search from January 1980 to April 2013.

\section{Appendix 4. CINAHL (EBSCO host) search strategy}

S1 (((MH "Oxygen Therapy") and intubation rates*)) OR ((high flow and (nasal or prong or cannula))) OR (nasal and oxygen)

S2 (MM "Randomized Controlled Trials") OR (MM "Random Assignment") OR (MH "Clinical Trials+") OR (MM "Multicenter Studies") OR (MM "Prospective Studies") OR (MM "Placebos") OR (MM "Double-Blind Studies") OR (MM "Triple-Blind Studies") OR (MM "Single-Blind Studies") S3 S1 and S2

Seach from 1982-April 2013.

\section{Appendix 5. LILACS search strategy}

(oxygen therapy and intubation rates\$) or (high flow and (nasal or prong or cannula)) or (nasal and oxygen) [Palabras] Search from 1982 to April 2013.

Appendix 6. Data extraction form

\section{Review title or ID}

Study ID (surname of first author and year first full report of study was published e.g. Smith 2001)

Report IDs of other reports of this study (e.g. duplicate publications, follow-up studies) 


\section{General information}

Date form completed ( $d d / \mathrm{mm} /$ yyyy)

Name/ID of person extracting data

\section{Report title}

(title of paper/abstract/report from which data are extracted)

\section{Report ID}

(ID for this paper/abstract/report)

\section{Reference details}

\section{Report author contact details}

\section{Publication type}

(e.g. full report, abstract, letter)

\section{Study funding sources}

(including role of funders)

\section{Possible conflicts of interest}

(for study authors)

\section{Notes:}

\section{Study eligibility}




\begin{tabular}{|c|c|c|c|c|c|}
\hline $\begin{array}{l}\text { Study } \\
\text { character- } \\
\text { istics }\end{array}$ & $\begin{array}{l}\text { Eligibility criteria } \\
\text { (insert eligibility criteria for each characteristic as defined } \\
\text { in the protocol) }\end{array}$ & Yes & No & Unclear & $\begin{array}{l}\begin{array}{l}\text { Location in } \\
\text { text }\end{array} \\
\text { (pg\& \&/fig/ } \\
\text { table) }\end{array}$ \\
\hline \multirow{2}{*}{$\begin{array}{l}\text { Type of } \\
\text { study }\end{array}$} & Randomized controlled trial & & & & \\
\hline & $\begin{array}{l}\text { Controlled clinical trial } \\
\text { (quasi-randomized trial) }\end{array}$ & & & & \\
\hline
\end{tabular}

$\begin{array}{ll}\begin{array}{l}\text { Partici- } \\ \text { pants }\end{array} & \begin{array}{l}\text { Paediatric patients from four weeks corrected to } 16 \text { years } \\ \text { of age }\end{array}\end{array}$

\begin{tabular}{ll}
\hline $\begin{array}{l}\text { Types of } \\
\text { interven- } \\
\text { tions }\end{array}$ & $\begin{array}{l}\text { High-flow nasal oxygen (heated/humidified, flow > 2 L/kg/ } \\
\text { min) } \\
\text { Comparator: non-invasive respiratory support such as } \\
\text { cot/tent/hood, low-flow oxygen or CPAP }\end{array}$ \\
\hline $\begin{array}{l}\text { Types of } \\
\text { outcome } \\
\text { measures }\end{array}$ & $\begin{array}{l}\text { Hospital mortality; intubation rate; treatment failure } \\
\text { length of hospital stay; clinical severity score; length of }\end{array}$ \\
& $\begin{array}{l}\text { PICU stay; complications-air leak, nasal trauma, nosoco- } \\
\text { mial sepsis, barotrauma, gastrointestinal distention }\end{array}$ \\
\hline
\end{tabular}

INCLUDE EXCLUDE

\section{Reason for exclusion}

\section{Notes:}

\section{Methods}

\section{Aim of study}


(Continued)

\section{Design (e.g. parallel, cross-over, cluster)}

\section{Unit of allocation}

(by individuals, cluster/groups or body parts)

\section{Start date}

\section{End date}

\section{Total study duration}

\section{Ethical approval needed/obtained for study}

Yes No Unclear

\section{Notes:}

\section{Risk of bias assessment}

See Chapter 8 of the Cochrane Handbook for Systematic Reviews of Interventions (Higgins 2011).

\begin{tabular}{|c|c|c|c|c|c|}
\hline \multirow[t]{2}{*}{ Domain } & \multicolumn{3}{|c|}{ Risk of bias } & \multirow{2}{*}{$\begin{array}{l}\text { Support for judge- } \\
\text { ment }\end{array}$} & \multirow{2}{*}{$\begin{array}{l}\text { Location in } \\
\text { text } \\
\text { (pg \& } \uparrow / f i g / t a- \\
\text { ble) }\end{array}$} \\
\hline & Low risk & High risk & Unclear & & \\
\hline
\end{tabular}

\section{Random sequence generation}

(selection bias)

\section{Allocation concealment}

(selection bias)

\section{Blinding of participants and per-} sonnel

(performance bias)

\section{Outcome group:}

all/

\section{Outcome group:}

\section{Blinding of outcome assessment}

(detection bias)
Outcome group:

all/

(if required)

Outcome group: 
(Continued)

\section{Incomplete outcome data}

(attrition bias)

\section{Selective outcome reporting?}

(reporting bias)

\section{Other bias}

\section{Notes:}

\section{Participants}

Provide overall data and, if available, comparative data for each intervention or comparison group.

Description as stated in report/paper

\section{Location in text}

(pg \& $\mathbf{\uparrow / f i g / t a b l e ) ~}$

\section{Total no. randomly assigned}

(or total population at start of study for NRCTS)

\section{Clusters}

(if applicable, no., type, no. people per cluster)

\section{Withdrawals and exclusions}

(if not provided below by outcome)

\section{Age}

Sex

\section{Severity of illness}

\section{Co-morbidities}

Other treatment received (additional to study intervention)

\section{Subgroups measured}

\section{Subgroups reported}

\section{Notes:}


6. Intervention groups

Copy and paste table for each intervention and comparison group.

Intervention group 1

Description as stated Location in text

in report/paper

(pg \& $\mathbf{q} /$ fig/table)

\section{Group name}

HFNC

\section{No. randomly assigned to group}

(specify whether no. people or clusters)

Description (include sufficient detail for replication, e.g. content, dose, compo-

nents)

\section{Duration of treatment period}

Timing (e.g. frequency, duration of each episode)

Delivery (e.g. mechanism, medium, intensity, fidelity)

\section{Co-interventions}

\section{Notes:}

\section{Comparison group 1}

Description as stated in report/paper

Invasive ventilation

\section{Group name}

\section{No. randomly assigned to group}

(specify whether no. people or clusters) 
(Continued)

Description (include sufficient detail for replication, e.g. content, dose, components)

\section{Duration of treatment period}

Timing (e.g. frequency, duration of each episode)

Delivery (e.g. mechanism, medium, intensity, fidelity)

\section{Co-interventions}

\section{Notes:}

\section{Comparison group 2}

\section{Description as stated} in report/paper

Noninvasive ventila-

Group name

\section{Location in text}

(pg \& $\uparrow /$ fig/table)

\section{No. randomly assigned to group}

(specify whether no. people or clusters)

Description (include sufficient detail for replication, e.g. content, dose, components)

\section{Duration of treatment period}

Timing (e.g. frequency, duration of each episode)

Delivery (e.g. mechanism, medium, intensity, fidelity)

\section{Co-interventions}

Notes:

\section{Outcomes}

Copy and paste table for each outcome. 


\section{Outcome 1}

Description as stated in report/paper

Location in text

(pg \& $\mathbf{q} /$ fig/table)

\begin{tabular}{ll}
\hline Outcome name & Hospital mortality \\
\hline Time points measured & \\
\hline Time points reported &
\end{tabular}

\section{Time points reported}

Outcome definition (with diagnostic criteria if relevant)

\section{Person measuring/reporting}

\section{Unit of measurement}

(if relevant)

Scales: upper and lower limits (indicate whether high or low score is good)

\section{Is outcome/tool validated?}

Yes No Unclear

\section{Imputation of missing data}

(e.g. assumptions made for ITT analysis)

\section{Assumed risk estimate}

(e.g. baseline or population risk noted in Background)

\section{Power}

Notes:

Outcome 2

Description as stated in report/paper

\section{Location in text}

(pg \& $\mathbf{q} /$ fig/table)

\section{Outcome name}

Intubation rate

\section{Time points measured}


(Continued)

\title{
Time points reported
}

Outcome definition (with diagnostic criteria if relevant)

\section{Person measuring/reporting}

\section{Unit of measurement}

(if relevant)

Scales: upper and lower limits (indicate whether high or low score is good)

\section{Is outcome/tool validated?}

Yes No Unclear

\author{
Imputation of missing data \\ (e.g. assumptions made for ITT analysis)
}

\section{Assumed risk estimate}

(e.g. baseline or population risk noted in Background)

\section{Power}

\section{Notes:}

\section{Outcome 3}

\section{Description as stated in report/paper}

Location in text

(pg \& $/ /$ fig/table)

\section{Outcome name}

Treatment failure-escalation to other

form of respiratory support

\section{Time points measured}

\section{Time points reported}

Outcome definition (with diagnostic criteria if relevant)

\section{Person measuring/reporting}

\section{Unit of measurement}

(if relevant)

Scales: upper and lower limits (indicate whether high or low score is good)

\section{Is outcome/tool validated?}




\section{Imputation of missing data}

(e.g. assumptions made for ITT analysis)

\section{Assumed risk estimate}

(e.g. baseline or population risk noted in Background)

\section{Power}

Notes:

\section{Time points measured}

\section{Time points reported}

Outcome definition (with diagnostic criteria if relevant)

\section{Person measuring/reporting}

\section{Unit of measurement}

(if relevant)

\section{Scales: upper and lower limits (indicate whether high or low} score is good)

\section{Is outcome/tool validated?}

Yes No Unclear

\section{Imputation of missing data \\ (e.g. assumptions made for ITT analysis)}

\section{Assumed risk estimate}

(e.g. baseline or population risk noted in Background)

\section{Power}

\section{Notes:}




\section{Outcome 5}

\section{Description as stated in report/paper}

Location in text

(pg \& $\uparrow /$ fig/table)

\section{Outcome name}

Complications-air leak, nasal trauma, nosocomial sepsis, barotrauma, gastroin-

testinal distention

\section{Time points measured}

\section{Time points reported}

Outcome definition (with diagnostic criteria if relevant)

\section{Person measuring/reporting}

\section{Unit of measurement}

(if relevant)

Scales: upper and lower limits (indicate whether high or low score is good)

\section{Is outcome/tool validated?}

Yes No Unclear

Imputation of missing data

(e.g. assumptions made for ITT analysis)

\section{Assumed risk estimate}

(e.g. baseline or population risk noted in Background)

\section{Power}

Notes:

\section{Outcome 6}




\section{Outcome name}

\section{Length of hospital stay}

\section{Time points measured}

\section{Time points reported}

Outcome definition (with diagnostic criteria if relevant)

\section{Person measuring/reporting}

\section{Unit of measurement}

(if relevant)

Scales: upper and lower limits (indicate whether high or low score is good)

\section{Is outcome/tool validated?}

Yes No Unclear

Imputation of missing data

(e.g. assumptions made for ITT analysis)

\section{Assumed risk estimate}

(e.g. baseline or population risk noted in Background)

\section{Power}

Notes:

\section{Outcome 7}

\section{Description as stated in report/paper}

Location in text

(pg \& $\mathbf{q} /$ fig/table)

\section{Outcome name}

Clinical severity score

\section{Time points measured}

\section{Time points reported}

Outcome definition (with diagnostic criteria if relevant) 
(Continued)

\title{
Person measuring/reporting
}

\section{Unit of measurement}

(if relevant)

Scales: upper and lower limits (indicate whether high or low score is good)

Is outcome/tool validated?

Yes No Unclear

\author{
Imputation of missing data \\ (e.g. assumptions made for ITT analysis)
}

\section{Assumed risk estimate}

(e.g. baseline or population risk noted in Background)

\section{Power}

Notes:

Outcome 8: secondary outcome

Description as stated in report/paper

Location in text

(pg \& $\mathbf{q} /$ fig/table)

\section{Outcome name}

\section{Length of PICU stay}

\section{Time points measured}

\section{Time points reported}

Outcome definition (with diagnostic criteria if relevant)

\section{Person measuring/reporting}

\section{Unit of measurement}

(if relevant)

Scales: upper and lower limits (indicate whether high or low score is good)

\section{Is outcome/tool validated?}




\section{Imputation of missing data}

(e.g. assumptions made for ITT analysis)

\section{Assumed risk estimate}

(e.g. baseline or population risk noted in Background)

\section{Power}

Notes:

\section{Results}

Copy and paste the appropriate table for each outcome, including additional tables for each time point and subgroup as required.

\section{Dichotomous outcome}




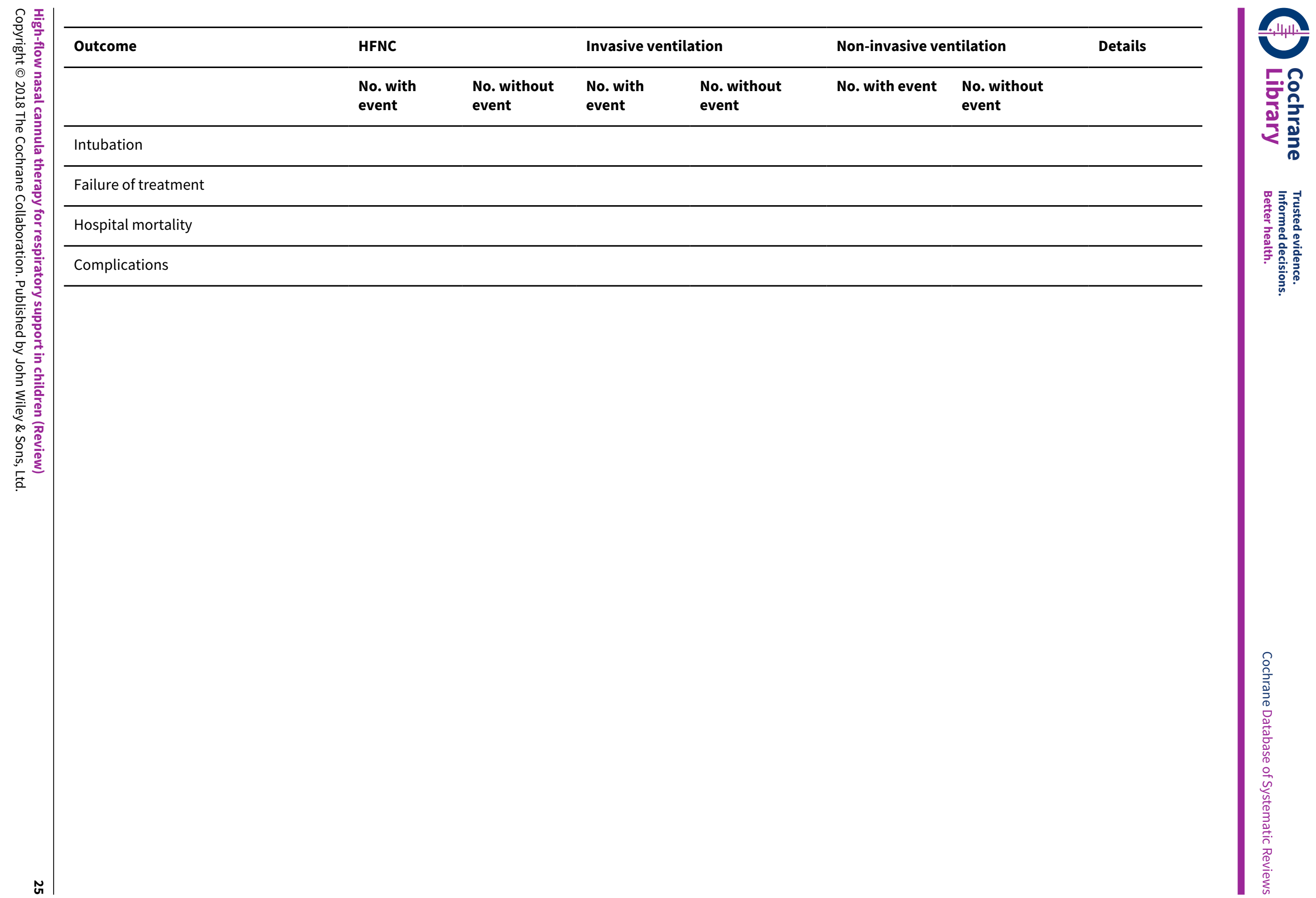




\section{Continuous outcome}




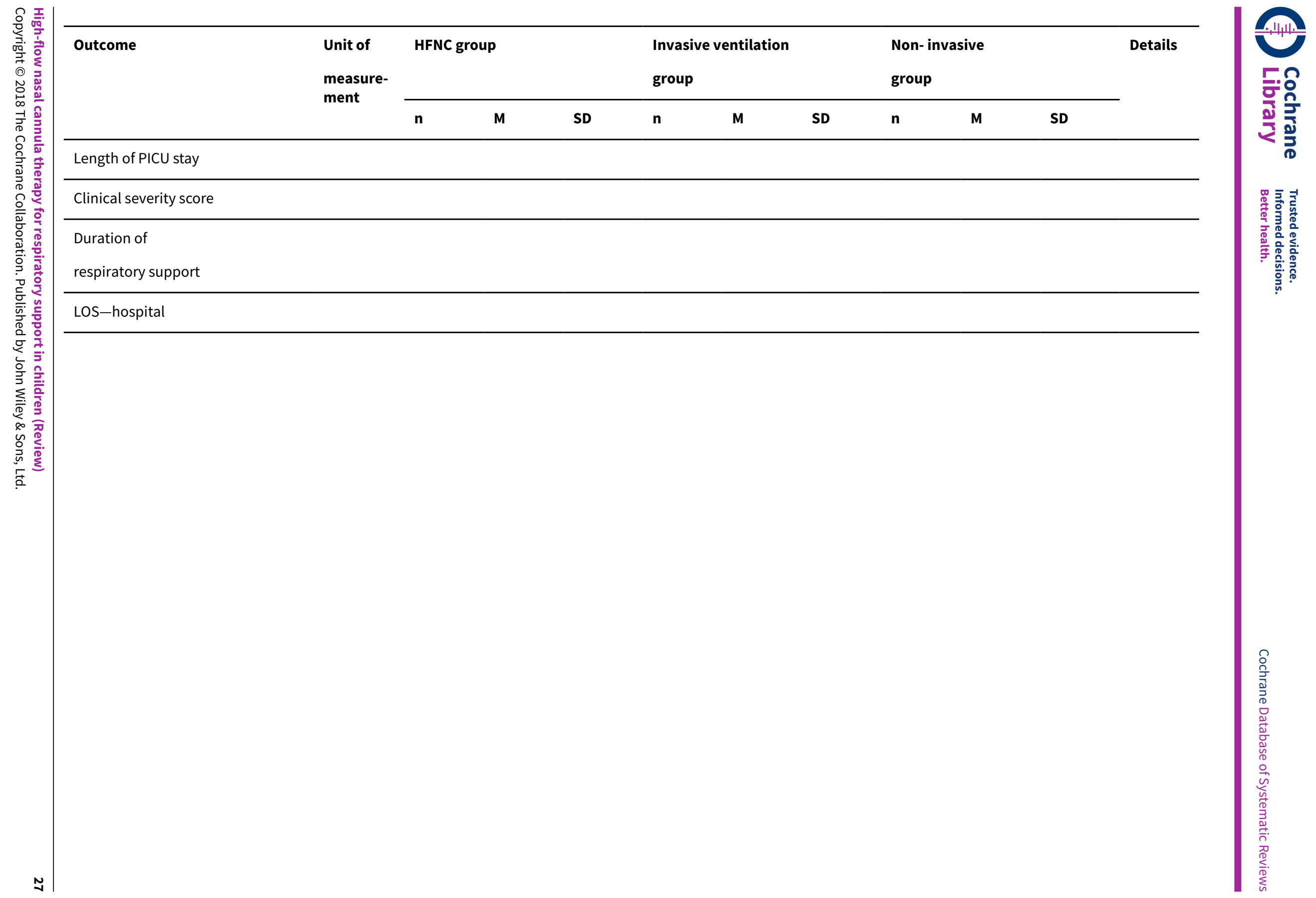




\section{Applicability}

Have important populations been excluded from the study? (consider dis-

advantaged populations and possible differences in the intervention effect)

Yes No Unclear

Is the intervention likely to be aimed at disadvantaged groups? (e.g. lower socioeconomic groups)

Yes No Unclear

Does the study directly address the review question?

(any issues of partial or indirect applicability)

Yes No Unclear

\section{Notes:}

\section{Other information}

Description as stated in report/paper

\section{Location in text}

(pg \& $\uparrow /$ fig/table)

\section{Key conclusions of study authors}

\section{References to other relevant studies}

\section{Correspondence required for further study information (from whom, what} and when)

\section{Notes:}

\section{WHAT'S NEW}

\begin{tabular}{lll}
\hline Date & Event & Description \\
\hline 20 December 2018 & Amended & Editorial team changed to Cochrane Emergency and Critical Care \\
\hline
\end{tabular}

\section{CONTRIBUTIONS OF AUTHORS}

Conceiving of the review: Sara Mayfield (SM).

Co-ordinating the review: SM. 
Undertaking manual searches: SM.

Screening search results: SM and Jacqui Jauncey-Cooke (JJ-C).

Organizing retrieval of papers: SM.

Screening retrieved papers against inclusion criteria: SM and JJ-C.

Appraising quality of papers: SM, JJ-C and Judith L Hough (JH).

Abstracting data from papers: SM and JJ-C.

Writing to authors of papers for additional information: SM.

Providing additional data about papers: SM.

Obtaining and screening data on unpublished studies: SM.

Managing data for the review: SM, JJ-C and Fiona Bogossian (FB).

Entering data into Review Manager (RevMan 5.2): SM.

Interpreting data: SM, JJ-C, FB, JH and Andreas Schibler (AS).

Making statistical inferences: SM, JJ-C, FB and Kristen Gibbons (KG).

Writing the review: SM.

Serving as guarantor for the review (one author): FB.

Taking responsibility for reading and checking the review before submission: JJ-C, FB, AS and JH.

\section{DECLARATIONS OF INTEREST}

Sara Mayfield and Andreas Schibler have received financial and equipment support from Fisher Paykel Healthcare to conduct two observational studies involving HFNC therapy. These studies would not be eligible for inclusion in this review.

Jacqueline Jauncey-Cooke: none known.

Judith L Hough: none known:

Kristen Gibbons: none known.

Fiona Bogossian: none known.

\section{DIFFERENCES BETWEEN PROTOCOLAND REVIEW}

Initially we planned to include all paediatric patients requiring HFNC therapy; however, because of the overlap with another Cochrane Review of HFNC in infants with bronchiolitis (Beggs 2012), we excluded children with bronchiolitis from our review.

\section{N DEX TERMS}

\section{Medical Subject Headings (MeSH)}

Masks; Oxygen Inhalation Therapy [*methods]; Respiration, Artificial [ ${ }^{*}$ methods]

\section{MeSH check words}

Child; Humans 